\title{
Seeing the wood for the trees: land-use legacies in native woodland
}

\author{
Aileen Cudmore \\ School of Biological, Earth and Environmental Sciences, UCC
}

\section{Introduction}

Native deciduous woodland in Ireland covers less than $2 \%$ of the entire country. The scarcity of this national resource means that all remaining native woodland is of great conservation importance. However, any attempt to restore and preserve existing native woodland must consider all factors that contribute to its current status and condition. These include features such as climate, elevation, soil, threats from invasive species (nonnative plant and animal species that adversely affect the habitats they occupy), as well as current and future management practices. However, one key factor that is often overlooked is the former history of the woodland, not only in recent decades, but also over the past few centuries. Unlike many other habitats (such as lakes, rocky shores, or rivers), historical management can have major impacts on current woodland structure and functioning; for instance, it can promote the survival of certain plant and animal species over others, and it can also alter environmental conditions (such as nutrient availability, hydrology, and soil structure). This work aims to gain a greater understanding of the effects of past land-use on various aspects of present-day native deciduous woodland in Ireland.

\section{Woodland history}

Almost all woodlands, even those of natural origin, have experienced some form of management or disturbance event in the past. Indeed, human activities have had an enormous effect on much of the current wooded area in western Europe and eastern North America for many hundreds and even thousands of years. Woodlands have been traditionally used for a wide variety of purposes; they were frequently used to coppice wood for timber, to graze cattle and pigs, and as a supply of food, fuel and herbs. However, undoubtedly the most severe human impact on woodlands was the removal of trees and conversion to agricultural land.

In Ireland, the first significant woodland clearances occurred during the Neolithic period, nearly 6000 years ago, and have continued throughout history to the present-day. Although trees and woodland-associated plants and animals will readily re-colonise cleared 
areas, these past disturbances have greatly affected the existing species composition and age structure of many existing woodlands. In addition, the complex history of Irish woodlands means that current woods are now often a result of several phases of deforestation and reforestation; consequently, even sections within an individual wood can have contrasting land-use histories. An assessment of the past history and management of Irish woodlands is therefore crucial to inform future management decisions. However, the importance of land-use history is only now beginning to be recognised. Consequently, the objective of this research is to explicitly investigate the impacts of land-use legacies on present-day plant and animal ecology, as well as woodland structure and functioning.

The continuous and widespread influence of humans on woodlands means that all "primary woodland", i.e., natural woodland which arose after the end of the last Ice Age and has never been significantly influenced by people, has long been lost. However, despite the extensive effects of human activities, two main types of woodland can still be discerned, based on their land-use history. "Ancient woodlands" are those that have been continuously wooded since at least the time of the oldest available historical data, while "secondary woodlands" are those that have established on former agricultural land after that date. In Ireland, this threshold date is acknowledged to be 1660, which corresponds to the time during which the Down Survey maps were produced. While these maps were created to facilitate the confiscation of land following the Cromwellian invasion, they also represent the first accurate depiction of woodlands in Ireland.

\section{Study site}

A recent inventory of woodland in Ireland found that only 123 individual stands (groups of trees) of ancient woodland still remain throughout the entire country. Most of these woodlands are poorly studied; often the only information available is a cursory description of their plant communities. Because of the rarity of these sites, our study centred on just a single ancient woodland, the Gearagh in County Cork (N 51 $\left.52^{\prime} 09^{\prime \prime}, \mathrm{W} 9^{\circ} 01^{\prime} 00^{\prime \prime}\right)$. While the core of this woodland can be classified as "ancient", parts of the outer sections are of secondary origin. A multi-disciplinary approach was used to compare the origin, development, and ecological functioning of these ancient and secondary areas; detailed investigations were carried out into the history, geography, soil properties (including types of seed present), vegetation composition, and soil and ground-dwelling invertebrate communities of the sites. As the areas of woodland of different age lie adjacent to each other, and are subject to the same climatic and environmental conditions, any differences between the sites can be attributed to their contrasting land-use histories.

The continued existence of the Gearagh as woodland, rather than pastureland, is due partly to its geographical setting, and also due to land-ownership boundaries. The core of the Gearagh is composed of a series of wooded islands along a $7 \mathrm{~km}$ anastomosing stretch 
(rivers with multiple, interconnected, coexisting channels with stable, vegetated islands) of the river Lee, near Macroom. In the past, these wooded islands were protected from exploitation by the surrounding network of river channels. Such anastomosing river systems are a notable feature of rivers in this part of south-west Ireland. For instance, similar woodlands once existed on the river Bandon near Dunmanway, and on the river Bride to the west of Cork city. A historical account describes how the latter was cleared and drained during the early 1700 s as part of a land improvement scheme. While attempts were also made to drain and straighten the river Lee along the Gearagh, these improvements proved much more difficult to maintain and were ultimately abandoned.

It is with the first Ordnance Survey map from 1842 that detailed features of the Gearagh can be seen for the first time. This map clearly shows the areas that had been cleared for agriculture, which have now re-established as secondary woodland and other areas which have remained as woodland to the present day. The cleared and wooded areas corresponded to land-ownership boundaries. Extensive relict flood protection walls are still to be seen in the previously cleared land, indicative of the cost and effort needed to maintain grazing land along the river. Evidently, the owner of the land that was not cleared had little interest in investing in such work. The ancient woodland area therefore remained relatively undisturbed and survived throughout this period of intensive modification of the Irish landscape.

\section{Main findings}

The results of this research show that removal of the tree canopy and conversion of the land to pasture during the 1800s had many direct and indirect impacts on the ecology of the secondary woodland area (see Fig. 1). Soil surveys were carried out in the ancient and secondary woodland, with a view to determining the effect of past agriculture on nutrient availability and cycling within the woodland. The study shows that the ancient woodland contains a remarkably undisturbed soil, confirming the lack of human impact in this site. The soil is of a uniformly deep dark brown colour and is extremely well-drained, corresponding to a so-called "typical brown earth" soil, which developed naturally in woodland since the end of the last Ice Age. On the other hand, the soil of the secondary woodland site is denser and of a lighter colour. The historical removal of the tree canopy increased the amount of water percolating through the soil; this downward movement of water also carried various nutrients with it, depositing them at greater depths in the soil, beyond the reach of most plant roots. Farmers therefore had to apply organic fertilisers and lime in order to maintain the fertility of the soil. Indeed, liming was common in the late 1800s, and high amounts of calcium were recorded in parts of the secondary woodland in the Gearagh.

While the same tree species were found in both the ancient and secondary sites, the com- 


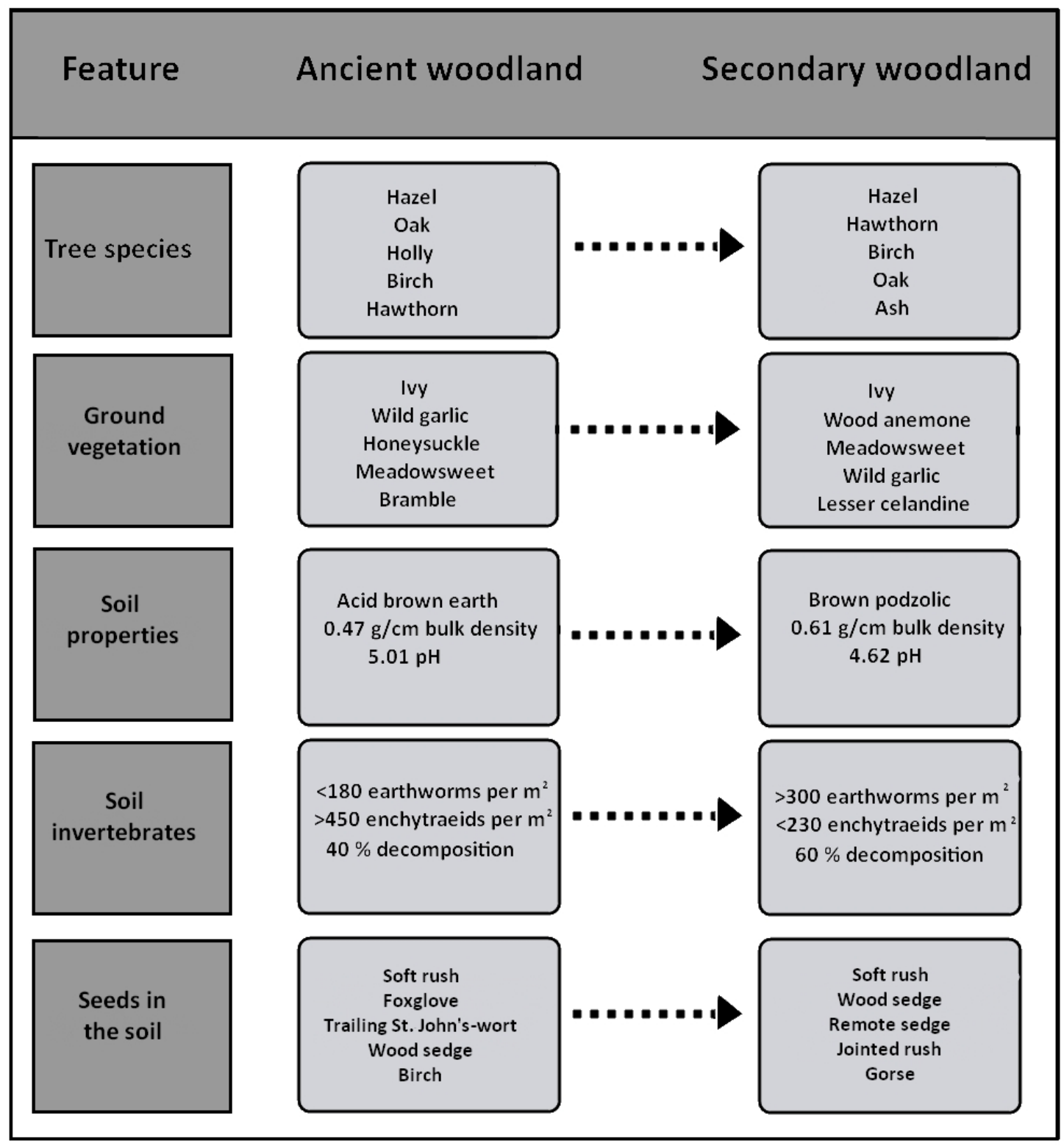

Figure 1: : Summary of the main differences between the ancient and secondary woodland areas of the Gearagh.

munity distribution and species composition of the ground vegetation layer differed considerably between the two areas. The changes in the soil structure as a result of past land-use created a more poorly drained soil in the secondary sites. This is reflected by an increase in moisture-tolerant species in the secondary site compared with the ancient woodland. Seeds associated with typical grassland species were also found in the secondary site, but were less abundant in the ancient woodland.

The alteration of soil and environmental conditions as a result of historical agricultural use also appears to have had a major influence on soil and ground-dwelling invertebrates in the Gearagh. For instance, conversion to agriculture encouraged the proliferation of 
large lumbricid earthworms at the expense of smaller enchytraeid potworms, which are far more abundant in the ancient woodland. The soil microbial community also differs considerably between the sites. In addition, these changes appear to have greatly affected processes such as leaf litter decomposition and nutrient cycling, which have important consequences for ecosystem functioning. Very little is known about the biodiversity and functioning of these ancient woodland soils, as they are extremely rare in western Europe.

\section{Conclusion}

It is clear that the structure and function of Irish woodlands can be substantially altered by past human activities, and that these land-use legacies can persist for hundreds of years after woodland re-establishes. Although the above-ground vegetation of ancient and secondary woodland sites appears superficially similar, the sites actually differ significantly in a number of ways. This research highlights the importance of changes in soil conditions as a result of past land-use, and the effect that this can have on both the below-ground and above-ground communities. Detailed historical information is therefore vital for the successful conservation and restoration of our remaining woodlands.

Aileen Cudmore is a student in the School of Biological, Earth and Environmental Sciences, under the supervision of Dr. Simon Harrison and Professor Peter Jones. The author would like to acknowledge the Irish Research Council for Science, Engineering and Technology (IRCSET) for funding this research. 